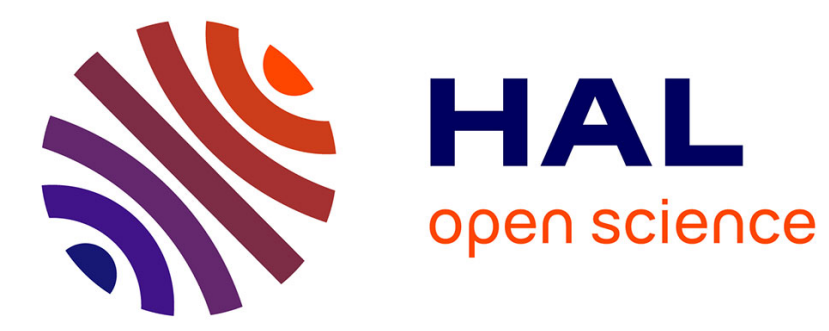

\title{
Preparation of perfluorocarbon emulsions by premix membrane emulsification for Acoustic Droplet Vaporization (ADV) in biomedical applications
}

\author{
Romain Melich, Ali Zorgani, Frédéric Padilla, Catherine Charcosset
}

\section{To cite this version:}

Romain Melich, Ali Zorgani, Frédéric Padilla, Catherine Charcosset. Preparation of perfluorocarbon emulsions by premix membrane emulsification for Acoustic Droplet Vaporization (ADV) in biomedical applications. Biomedical Microdevices, 2020, 22 (3), 10.1007/s10544-020-00504-5 . hal-03028857

\section{HAL Id: hal-03028857 https://hal.science/hal-03028857}

Submitted on 27 Nov 2020

HAL is a multi-disciplinary open access archive for the deposit and dissemination of scientific research documents, whether they are published or not. The documents may come from teaching and research institutions in France or abroad, or from public or private research centers.
L'archive ouverte pluridisciplinaire HAL, est destinée au dépôt et à la diffusion de documents scientifiques de niveau recherche, publiés ou non, émanant des établissements d'enseignement et de recherche français ou étrangers, des laboratoires publics ou privés. 


\title{
Preparation of perfluorocarbon emulsions by premix membrane emulsification for Acoustic Droplet Vaporization (ADV) in biomedical applications
}

\author{
Romain Melich $^{\mathrm{a}, \mathrm{b}}$, Ali Zorgani ${ }^{\mathrm{b}}$, Frédéric Padilla $\mathrm{b}^{\mathrm{b}, \mathrm{c}, \mathrm{d}, *}$, Catherine Charcosset ${ }^{\mathrm{a}, *}$ \\ ${ }^{a}$ Univ Lyon, Université Claude Bernard Lyon 1, CNRS, LAGEPP UMR 5007, 43 boulevard du 11 novembre 1918, F-69100, \\ VILLEURBANNE, France \\ ${ }^{b}$ LabTAU, INSERM, Centre Léon Bérard, Université Lyon 1, Univ-Lyon, F-69003, LYON, France \\ ${ }^{c}$ Department of Radiology, University of Virginia School of Medicine, Charlottesville, VA, USA \\ ${ }^{d}$ Focused Ultrasound Foundation, 1230 Cedars Court, Suite 206, Charlottesville, VA, USA
}

\begin{abstract}
Perfluorocarbon (PFC) droplets are used in acoustic droplet vaporization (ADV), a phenomenon where droplets vaporize into gas microbubbles under exposure to ultrasound. The size and the size distribution of a phase change contrast agent is an important factor in determining the ADV threshold and the biodistribution. Thus, high throughout manufacturing of uniform-sized droplets, required to maintain spatial control of the vaporization process, remains challenging. This work describes a parametric evaluation of a novel process using premix membrane emulsification (PME) to produce homogeneous PFC emulsions at high rate with moderate pressure using Shirasu Porous Glass (SPG) membranes. In this study, we investigated the effect of several process parameters on the resulting pressure and droplet size: membrane pore size, flow rate, and dispersed phase type. The functionality of the manufactured emulsions for ADV was also demonstrated. Vaporization of the PFC emulsions was obtained using an imaging ultrasound transducer at $7.813 \mathrm{MHz}$, and the ADV thresholds were determined. Here, the pressure threshold for ADV was determined to be $1.49 \mathrm{MPa}$ for uniform-sized perfluorohexane (PFHex) droplets with a mean size of $1.51 \mu \mathrm{m}$ and a sharp distribution (CV and span respectively of $20 \%$ and 0.6 ). Thus, a uniform-sized droplet showed a more homogeneous vaporization with a uniform response in the focal region of the transducer. Indeed, polydispersed droplets had a more diffuse response outside the focal region due to the presence of large droplets that vaporize at lower energies. The ADV threshold of uniform-sized PFC droplets was found to decrease with the droplet diameter and the bulk fluid temperature, and to increase with the boiling temperature of PFC and the presence of an oil layer surrounding the PFC core.
\end{abstract}

Keywords: Emulsion, Premix membrane emulsification, Perfluorocarbon, Acoutic droplet vaporization, Homogeneous distribution

\footnotetext{
* Corresponding authors: Catherine Charcosset, Univ Lyon, Université Claude Bernard Lyon 1, CNRS, LAGEPP UMR 5007, 43 boulevard du 11 novembre 1918, F-69100, Villeurbanne, France. Tel.: +334724318 34 and Frédéric Padilla, Focused Ultrasound Foundation, 1230 Cedars Court, Suite 206, Charlottesville, VA, USA. Tel.: 434.284.9287.

Email addresses : catherine.charcosset@univ-lyon1.fr (Catherine Charcosset) and fpadilla@fusfoundation.org (Frédéric Padilla)
} 


\section{Introduction}

In acoustic droplet vaporization (ADV), an emulsion is converted into gas bubbles upon exposure to ultrasound energy beyond a vaporization threshold (Figure 1) 11, 2. Upon ultrasound exposure above the ADV threshold, gas nucleation and/or cavitation are initiated and trigger the phase transition. Ultrasounds

5 serve as a remote detonator to trigger the vaporization of the droplets in a controllable, non-invasive and also localized manner 3. These emulsions usually consist of surfactant stabilized droplets with a perfluorocarbon (PFC) liquid such as perfluoropentane (PFP, $C_{5} F_{12}, 29^{\circ} \mathrm{C}$ boiling point), perfluorohexane (PFHex, $C_{6} F_{14}$, $56^{\circ} \mathrm{C}$ boiling point) or perfluoroheptane (PFHep, $C_{7} F_{16}, 80^{\circ} \mathrm{C}$ boiling point). PFC droplets are interesting alternatives to microbubbles, for both imaging and drug delivery applications, as they are more stable and can circulate longer in the bloodstream before vaporization [2, 4].

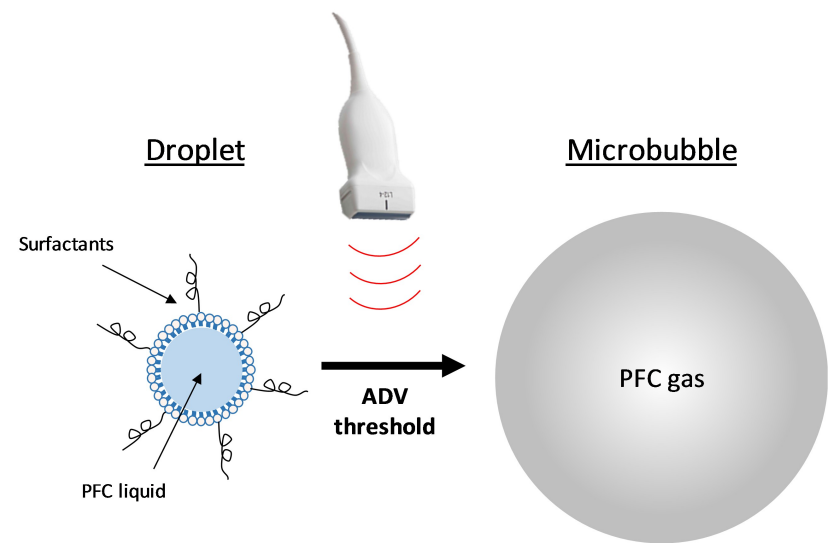

Figure 1: Schematic of Acoustic Droplet Vaporization (ADV) process. Vaporization of PFC droplets as a result of exposure to ultrasonic pulses leads to the formation of a gas bubble

With droplets in the micron and sub-micron range, the Laplace pressure exerted on the PFC liquid core is increased, enabling small droplets to be maintained in a liquid form even above their bulk fluid boiling point, such as physiological body temperature $\left(37^{\circ} \mathrm{C}\right)$ [1, 5. After vaporization, the gas bubbles formed are approximately 5 times larger in diameter than the initial droplets [2, 6]. The expansion ratio decreases with decreasing droplet size because of increased Laplace pressure, which is an inverse function of droplet radius. During ADV, the PFC liquid is converted into a gas in a nanosecond timeframe [7.

These droplets can be selectively vaporized into highly echogenic gas bubbles, with numerous applications to diagnosis and therapy [8. One of the most well studied applications of ADV is embolotherapy which enables vessel occlusion to limit blood flow in a specific tissue [9, 10. This technique has been proposed to treat renal carcinoma and to reduce blood supply for hypervascular tumors [3. A second major application of ADV agents is drug delivery, where encapsulated drugs are released specifically to the disease site while minimizing systemic effects [11, 12, 13. Other approaches include the use of droplets functionalized with 
molecular ligands to target specific cells, combining mechanical cell destruction with drug delivery [14, and the use of droplet vaporization combined with high intensity focused ultrasound to accelerate ultrasound thermal therapy [15].

The size and size distribution of ADV droplets is an important factor in determining the vaporization threshold, as larger droplets require less energy to vaporize than smaller ones [16, 17]. Also, in a polydisperse sample, the vaporization of larger droplets at lower energies could influence the ADV threshold of the smaller droplets. Monodispersed droplets can use the lowest acoustic pressure possible for vaporization, since all droplets respond similarly, therefore achieving the highest vaporization efficiency at the lowest acoustic pressure [10. Moreover, when using ADV to enhance contrast in ultrasound imaging, the level of acoustic enhancement varies with droplet size [18. In addition, the size and size distribution of PFC droplets is an important factor in term of biodistribution. For embolotherapy with ADV agents, uniform-sized droplets are needed to target a specific vascular diameter while not affecting other vessels [16], and to avoid undesirable vessel occlusion.

Conventional methods for producing PFC droplets include sonication [19, 20, and high-speed mechanical agitation [21, 22, 23] of the liquid PFC and the surfactant aqueous solution. These methods typically result in polydispersed droplet populations, sometimes requiring filtrations or differential centrifugation to reduce the size polydispersity [24, 25]. Precise size control of ADV droplets can be achieved by using microfluidic techniques. For example, Martz et al. [10] produced monodispersed liquid PFP droplets minimum size of approximately 7-20 $\mu \mathrm{m}$ through the use of a microfluidic device with flow focusing technology. Simons et al. [18] prepared monodispersed PFHex emulsions with size of 4 and $12 \mu \mathrm{m}$ using photolithographic microsieves. The emulsions provided enhanced echogenicity and the acoustic enhancement varied with the droplet size. However, the major limitation of microfluidic methods is low production rates $\left(10^{+4}-10^{+6}\right.$ Droplets/s $)$ which 45 is far below the rates acheived through mechanical agitation [26.

Membrane emulsification has emerged as an alternative technique to produce emulsions [27, 28] and microbubbles [29, 30] with controlled size. Two main configurations are used: direct membrane emulsification (DME) and premix membrane emulsification (PME). For the preparation of oil/water emulsions by DME, the dispersed phase (oil) is pushed through membrane pores and droplets form at the pore outlets detached in a crossflowing or stirring continuous phase. In PME, a coarse emulsion (premix) is first prepared before being pushed through the membrane pores [31, 27. Smaller droplets are formed by break-up of larger droplets in the membrane due to the shear stress at the pore walls. Higher flow rates are obtained in PME than DME, which is particularly attractive for the preparation of emulsions at large scales. Other advantages of PME over DME are the simplicity of the set-up and the easiest cleaning of the membrane. With PME, oil/water emulsions were obtained at high flow rates (up to $200 \mathrm{~mL} / \mathrm{min}$ ) and with Shirasu Porous Glass (SPG) membranes of pores down to $0.2 \mu \mathrm{m} \underline{32}$.

In this study, we report the preparation of emulsions for ADV by PME. An experimental set-up, previously developed to manufacture emulsions [32, was used to produce homogeneous emulsions with formulations 
suitable for ADV. We consider the homogeneous term corresponding to a narrow size distribution for droplet size with a coefficient of variation below $20 \%$. The set-up included a high pressure syringe pump connected to a SPG membrane module working at pressures up to 60 bar and flow rate of $200 \mathrm{~mL} / \mathrm{min}$. This set-up was developed in our labarotory with the advantages of higher pressures (up to 60 bar) compared to usual set-ups (6-8 bars), so smaller droplets can be obtained by using membranes with smaller pore sizes. The pressure through the membrane is a very important parameter, as it must be lower than the maximum pressure (60 bars) at which the membrane is broken. The effect of several parameters on the resulting pressure $\left(\Delta P_{r}\right)$ and the droplet size was investigated: process parameters (flow rate and membrane pore size) and formulation (the dispersed phase type). In a second part, these emulsions were characterized and tested for ADV. To summarize, we evaluated the feasibility of producing uniform-sized ADV agents by membrane emulsification and measured the influence of formulation parameters on the ADV threshold.

\section{Materials and methods}

\subsection{Materials}

Liquid PFHex and PFHep were purchased from Sigma Aldrich (France). The density of perfluorocarbon liquids are 1.68 g.cm ${ }^{-3}$ for PFHex and 1.72 g. $\mathrm{cm}^{-3}$ for PFHep. The oil phase Labrafac - Caprylic Capric Medium Chain Triglycerides (MCT oil) was purchased from Gattefossé (Saint-Priest, France) and has a density of 0.93-0.96 g.cm ${ }^{-3}$. The surfactants Polyoxyethylene (20) sorbitan monolaurate (Tween 20) and Polyoxyethylene (40) stearate (PEG40S) were purchased from Sigma Aldrich (France). Ultrapure water was obtained using a Synergy unit system (Millipore, France).

\section{2. $S P G$ membranes and membrane module}

Hydrophilic SPG membranes were purchased from SPG Technology Co. Ltd (Miyazaki, Japan). The tubular SPG membranes have a length of $125 \mathrm{~mm}$ and an inner diameter of $8.3 \mathrm{~mm}$. These membranes are manufactured by a phase separation process of calcium aluminum borosilicate glass and subsequent acid leaching [33, 34] and have been widely used for production of emulsions and particles [27, 28. Membranes with mean pore size of 3.1, 1.1 and $0.8 \mu \mathrm{m}$ were investigated; the mean pore size data are given by the manufacturer. In most experiments, the mean pore size used was $1.1 \mu \mathrm{m}$.

The microstructure of the SPG membranes was observed by scanning electron microscopy (SEM) using a FEI Quanta 250 FEG microscope at the Centre Technologique des Microstructures at the University Lyon 1 (Villeurbanne, France). A fragment of the SPG membrane was deposited on a flat steel holder. The sample was coated under vacuum by cathodic sputtering with copper. The samples were observed by SEM under an accelerating voltage of $10 \mathrm{kV}$. SPG membranes have interconnected and cylindrical tortuous pores that form a three-dimensional network (Figure 2). The range of membrane porosity is $0.53-0.60$ [35]. The SPG membrane surface is negatively charged and hydrophilic due to the presence of hydroxyl groups such as silanol. The dissociation of the silanol groups gives the negative charge of the SPG membrane surface [29]. 
The membrane was installed inside a cross-flow module in stainless steel supplied by SPG Technology and connected to a high pressure pump. The effective length of the membrane was reduced to $105 \mathrm{~mm}$ due to sealing rings placed at both ends of the membrane tube. The effective membrane area was then $27.4 \mathrm{~cm}^{2}$.

\subsection{Experimental set-up and procedure}

The experimental set-up developed in our laboratory for the preparation of emulsions by PME is shown in Figure 2 [32. The set-up included a high pressure single cylinder pump BTSP 500-5 (Floxlab, Nanterre, France) connected to the SPG membrane module. The pump is composed of a motor-driven piston and is used to push the premix from a storage tank of $500 \mathrm{ml}$ through the membrane pores. The flow rate, pressure, and volume injected are recorded by a computer at 1 second intervals. The hydrodynamic resistance to water $\left(R_{m}\right)$ was measured and compared to the value obtained with an unused membrane before each experiment to ensure that the membrane had been properly cleaned.

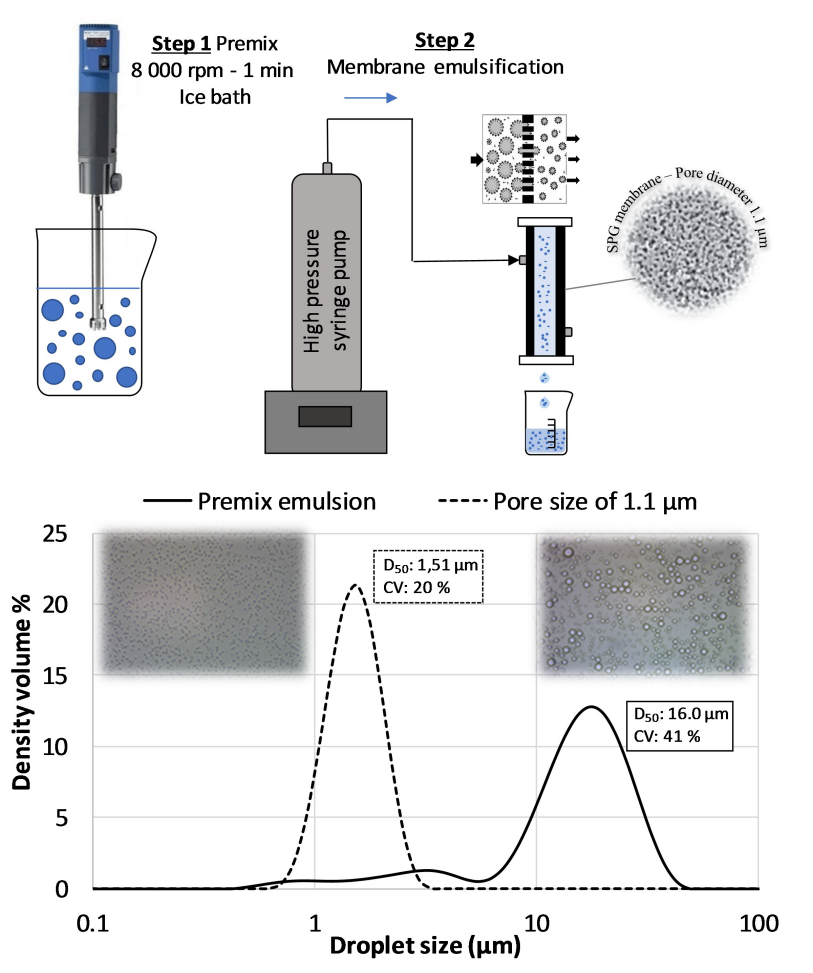

Figure 2: Experimental set-up of premix membrane emulsification with a high pressure syringe pump and SPG membrane (top). Perfluorocarbon droplet size distribution of the premix emulsion obtained by ultra-turrax and by premix membrane emulsification with a membrane pore size of $1.1 \mu \mathrm{m}$ at $200 \mathrm{~mL} / \mathrm{min}$. Observation by optical microscopy of both emulsions with a optical objectif $(40 \times)$ (bottom)

\subsection{Preparation of emulsions}

The homogeneous emulsions stabilized with Tween 20 and PEG40S were obtained by PME in two steps: first, by preparing a premix, and then by passing this premix through the SPG membrane pores. 
Premix preparation : The continuous phase was composed of 2.0wt\% Tween20:PEG40S at a molar ratio of 9:1 in water. Four dispersed phases were tested: PFHex, PFHep, MCT oil and a mixture of PFHex and MCT oil (50/50 vol\%). The premix emulsion was obtained by emulsification of 10 vol\% of dispersed phase in continuous phase, then mixed by a rotor stator homogenizer (T50 digital Ultra-turrax, S25N-18G, Ika) at $8000 \mathrm{rpm}$ for $1 \mathrm{~min}$. The beaker containing the premix was placed into an ice bath to avoid the evaporation of PFC due to the temperature increase created by the ultra-turrax device.

Preparation of uniform-sized droplets: The SPG membrane was placed inside the membrane module, and the module connected to the syringe pump. The premix was then introduced into the syringe pump tank at

115 a flow rate of $50 \mathrm{ml} \cdot \mathrm{min}^{-1}$. In most experiments, the premix was injected through the membrane pores at a flow rate of $200 \mathrm{ml} \cdot \mathrm{min}^{-1}$. The homogeneous emulsion obtained was collected into a beaker placed under the membrane module.

In this study, we investigated the influence of process parameters (flow rate and membrane pore size) and formulation parameters (dispersed phase type) on the droplet size and on the pressure generated by the pump through the membrane pores. For each parameter observed, three separate samples were prepared from one premix. The droplet size and the pressure values reported were the average of the three measurements.

\subsection{Physical characterization}

\subsubsection{Laser diffraction measurement}

The diameter and size distribution of droplets were measured using laser diffraction measurement, which yields volume-weighted distributions (Mastersizer 3000, Malvern Instrumentation, France). The technique is based on a reduction in intensity of a laser beam as it is scattered while passing through a sample containing dispersed particulate. The Mie-scattering theory was used to convert light scattering data to droplet size distribution. The refractive index of the dispersed phase was 1.2515 for PFHex, 1.265 for PFHep and 1.445 for MCT oil. The aqueous continuous phase had refractive index of 1.33. The results were expressed by $D_{50}$, the diameter corresponding to $50 \mathrm{vol} \%$ on the relative cumulative size distribution curve. Two parameters were used to characterize the width of the size distribution, first, the span of the droplet size distribution, expressed as:

$$
\text { Span }=\frac{D_{90}-D_{10}}{D_{50}}
$$

where $D_{90}$ and $D_{10}$ are the diameters corresponding to 90 and $10 \mathrm{vol} \%$ on the relative cumulative droplet size distribution curve, respectively.

Then, the polydispersity was also characterized by the coefficient of variation $(\mathrm{CV})$, which is a measure of the standard deviation $(\delta)$ at the droplet diameter $\left(D_{50}\right)$ expressed in $\%$, using the equation [36, 37, 38]:

$$
C V=\frac{\delta}{D_{50}} \times 100
$$


All measurements have been done in triplicate; the values reported were the average of the three measurements.

\subsubsection{Optical characterization}

For emulsions with the mix PFHex and MCT oil (50/50 vol\%) as dispersed phase, optical microscopy was used to determine how the two phases were separated inside the droplets. For that, the orange $3 \mathrm{G}$ dye (Solvent orange 60 powder, $\mathrm{C}_{18} \mathrm{H}_{10} \mathrm{~N}_{2} \mathrm{O}$ ) was solubilized into the MCT oil prior to droplets formation. After preparation of the emulsion, an aliquot of the emulsion was diluted and added to a Malassez counting chamber (Marienfeld-Superior) to observe the droplets by optical microscopy.

The observations were carried out with a microscope (Leica DM LM, France). A CCD video camera (Leica MC120 HD) was connected to the microscope to capture images, which were visualized with Leica Application Suite (LAS EZ) software (Version 3.4.0).

\subsection{Interfacial surface measurement}

The interfacial tensions of surfactant solutions with various dispersed phases were measured by the pendant drop method using a Drop Shape Analysis tensiometer model 100 DSA-10 Mk2 (Krüss). A rising droplet (volume approximately of $5 \mu \mathrm{l}$ ) of PFC or oil $(24 \mu \mathrm{l}$ ) was formed at the extremity of a needle using a syringe inside a quartz cell $(10 \mathrm{ml})$ containing $2.0 \mathrm{wt} \%$ of surfactant solution at room temperature. The formation time of the droplet was about $1 \mathrm{~s}$. The system was calibrated using the outer diameter of the needle (1.507 $\mathrm{mm})$. The shape of the droplet was imaged with a CMOS camera and extracted by image analysis, and the interfacial tension was obtained as the best fit of the theoretical drop shape to the experimental profile.

\subsection{Acoustical characterization}

\subsubsection{Acoustical device}

All vaporization experiments were performed with the same PFC volume, using a beaker containing 200 $\mathrm{mL}$ of water and $400 \mu \mathrm{L}$ of a suspension of droplets, resulting in a concentration of $2.0 \times 10^{+6}$ and $2.0 \times 10^{+8}$ droplets/mL for polydispersed and uniform-sized PFC droplets, respectively. The solution was heated and maintained at $37^{\circ} \mathrm{C}$, unless otherwise noted. The suspension was exposed to acoustic pulses emitted by a 7.813 MHz single-element transducer (Linear probe model L12-3V, 192 elements linear array, Verasonics, Kirkland WA, USA). The reference measurements of the pressure emitted by the linear array were kindly provided by Verasonics. The reference peak pressure was measured in water, using a membrane hydrophone with an active sensor diameter of $0.4 \mathrm{~mm}$ (model D1604, Precision Acoustics, Dorset, UK), a Vantage System and a linear L12-3V probe, same models but different from the system and probe used in our experiments. The emitting surface of the probe was placed $1 \mathrm{~cm}$ below the water surface. The probe was connected and driven by a Vantage System 256 (Verasonics, Kirkland WA, USA). Pulses were emitted using a beamforming sequence, in burst mode, 10 cycles per burst, at a pulse-repetition frequencies (PRF) of $1 \mathrm{kHz}$, for a total exposure time of $3 \mathrm{~s}$. The suspension was stirred by magnetic agitation to ensure homogenization of the 
droplets distribution in the solution, as the droplets tend to accumulate at the bottom of the beaker due to their density being greater than that of water. Incident acoustic pressure was increased between two successive sonication sequences, by increasing the voltage delivered to the imaging probe. To assess the formation of gas microbubbles from liquid droplets when the pressure reached the ADV threshold, B-mode imaging was performed in real time to detect the increase of echogenicity of the newly generated microbubbles. Gas microbubbles are hyper-echogenic because of the difference in acoustic impedance between droplets and bubbles in the water phase.

\subsubsection{Determination of the vaporization threshold}

The ADV threshold was determined using a methodology similar to that previously described by Kripfgans

et al. 1] and Fabiilli et al. 21]. The recorded B-mode images were analyzed by ImageJ and converted to grayscale. For each vaporization measurement, a rectangular region of interest (ROI) $40 \mathrm{~mm}$ large by $5 \mathrm{~mm}$ depth (32132 $\left.p x^{2}\right)$, centered on the natural focus of the probe was selected. The mean echo amplitude (MEA) over the ROI was calculated as the sum of the gray values of all the pixels of the ROI divided by the number of pixel and was obtained by the equation :

$$
M E A(n)=\frac{1}{N M} \sum_{j=1}^{M} \sum_{i=1}^{N} A(i, j)
$$
on the resulting pressure and droplet size. The resulting pressure $\left(\Delta P_{r}\right)$ is the pressure required at constant flow rate to pass the premix emulsion through the membrane pores, and is the sum of three pressures [31, 32]:

$$
\Delta P_{r}=\Delta P_{\text {pipe }}+\Delta P_{\text {flow }}+\Delta P_{\text {disruption }}
$$


where the pipe pressure, $\Delta P_{\text {pipe }}$ is the pressure required to pass the premix through the pipe connecting the high pressure syringe pump to the membrane device, which increases with emulsion viscosity and flow rate. $\Delta P_{\text {flow }}$ is the pressure required for overcoming the flow resistance through the membrane pores, which like $\Delta P_{\text {pipe }}$, increases with emulsion viscosity and flow rate. Lastly, $\Delta P_{\text {disruption }}$ is the pressure required to deform and break-up large droplets into smaller ones [31, 39]. In our experimental conditions with emulsions of relative low viscosity, $\Delta P_{\text {pipe }}$ is low compared to the flow pressure, $\Delta P_{\text {flow }}$, and disruption pressure, $\Delta P_{\text {disruption }}$.

As detailed in Materials and Methods, 2 wt\% of surfactant was used in the aqueous continuous phase as a low amount of surfactant would be preferred for future in vivo use of the droplets. The droplet size of the premix emulsion was between 10 and $20 \mu \mathrm{m}\left(D_{50}: 16 \mu \mathrm{m}\right)$ with a large size distribution (span: 1.46 and $\mathrm{CV}$ : 41\%). After being passed through the $1.1 \mu \mathrm{m}$ membrane, the droplet size of the coarse emulsion was reduced to $1.51 \mu \mathrm{m}$ and the size distribution was much sharper with a CV of $20 \%$ and a span of 0.6 (Figure 2). It is interesting to observe that only one pass through the membrane was necessary to produce uniform-sized droplets, thanks to the properties of the SPG membranes: i) a sufficiently large thickness (1 mm), ii) the highly interconnected and iii) tortuosity of pores that break-up the droplets [31, 40] compared with other membranes (e.g. micro-engineered membranes). Indeed, the membrane technique can produce droplets with a span close to the span of the SPG membrane pore size distribution, in the range of 0.4-0.6, corresponding to a coefficient of variation around 10-20\% 27, 41. Overall, these droplet size and size distribution were suitable for ADV applications.

\subsubsection{Effect of membrane pore size}

The influence of membrane pore size on droplet size and resulting pressure was investigated with the 3.1, 1.1 and $0.8 \mu \mathrm{m}$ pore size membranes. The droplet size was found to decrease with the membrane pore size, being equal to 4.41, 1.51 and $1.19 \mu \mathrm{m}$, respectively (Figure 3). Therefore, the droplet size, $D_{\text {droplet }}$ was a linear function of the membrane pore size, $D_{\text {pore }}$, with $D_{\text {droplet }} / D_{\text {pore }}: 1.42$ and $R^{2}: 0.99$ (Figure 3). Similar results have been reported for other emulsions obtained by PME with $D_{\text {droplet }} / D_{\text {pore }}$ in the range of 1.0-1.5 [27, 32], this ratio is lower than those reported in DME, for example a ratio of 3 [27]. The CV and span were not impacted by the membrane pore size, and were respectively equal to 0.6 and $20 \%$, indicating a rather homogeneous droplet size distribution.

In addition, the resulting pressure was found to increase with a decrease in membrane pore size (Figure 3). This drastic increase of the resulting pressure is caused by the increase of $\Delta P_{\text {flow }}$ due to the increase of membrane resistance with smaller pores, and the increased of $\Delta P_{d i s}$ due to the force necessary to fractionate smaller droplets into smaller pores. For the $0.8 \mu \mathrm{m}$ pore size membrane, the resulting pressure was equal to 53.8 bars. We tried to use even smaller pores, with a $0.6 \mu \mathrm{m}$ membrane. But even at 60 bars and low flow rates (down to $10 \mathrm{~mL} / \mathrm{min}$ ), the premix could not be forced through the pores, and the membrane was eventually damaged. 

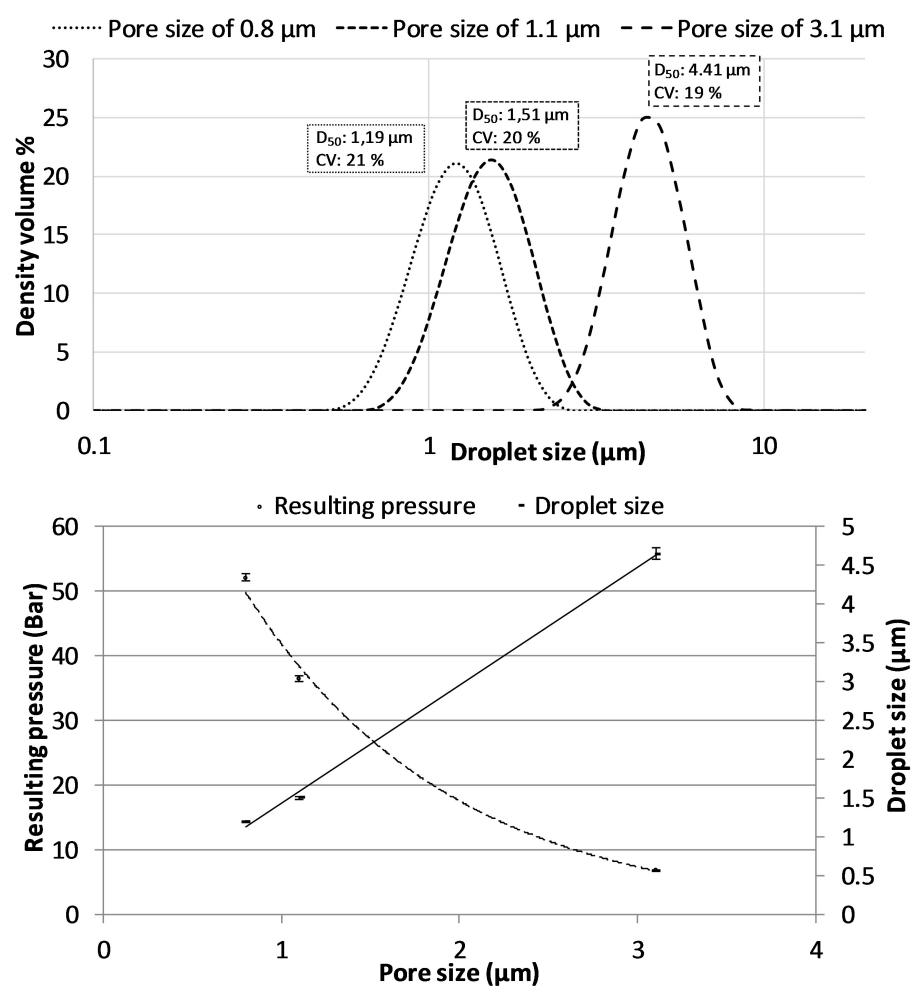

Figure 3: PFHexane droplet size distribution (top), droplet size and resulting pressure (bottom) of homogeneous emulsions obtained at different pore sizes 3.1, 1.1 and $0.8 \mu \mathrm{m}$ by membrane emulsification at $200 \mathrm{~mL} / \mathrm{min}$ (top)

\subsubsection{Effect of flow rate}

The effect of flow rate on droplet size and resulting pressure was observed using MCT oil as dispersed

phase (Figure 4). Flow rates between 10 and $200 \mathrm{~mL} / \mathrm{min}$ were investigated. The droplet size decreased slightly with increased flow rate, from $1.49 \mu \mathrm{m}$ to $1.38 \mu \mathrm{m}$ at 10 and $200 \mathrm{~mL} / \mathrm{min}$, respectively. Indeed, a higher flow rate leads to a higher wall shear stress into the membrane pores, that facilitates droplet disruption. The wall shear stress is given by the following equation:

$$
\tau_{w, p}=\frac{8 \eta_{e} J \xi}{\varepsilon D_{p}}
$$

where, $\eta_{e}$ is the viscosity of the emulsion, $\mathrm{J}$ is the transmembrane flux, $\xi$ is the pore tortuosity, $\varepsilon$ is the membrane porosity and $D_{p}$ is the pore diameter [39]. The CV and span also decreased slightly when increasing the flow rate, and thus the wall shear stress.

The resulting pressure for the preparation of uniform-sized droplets is shown in Figure 4 At higher flow rates, the pressure increase was proportional to the flow rate [31, 39] as expected from Darcy's law. The main advantage of working at high flow rate is to produce emulsions at high rate. In PME, high flow rates can be set, without negative effects on droplet size and size distribution, even if lower surfactant concentrations are used. Indeed, the yield obtained for PME were $\sim 10^{+12}$ Droplets/s compared to $10^{+4}-10^{+6}$ Droplets/s 

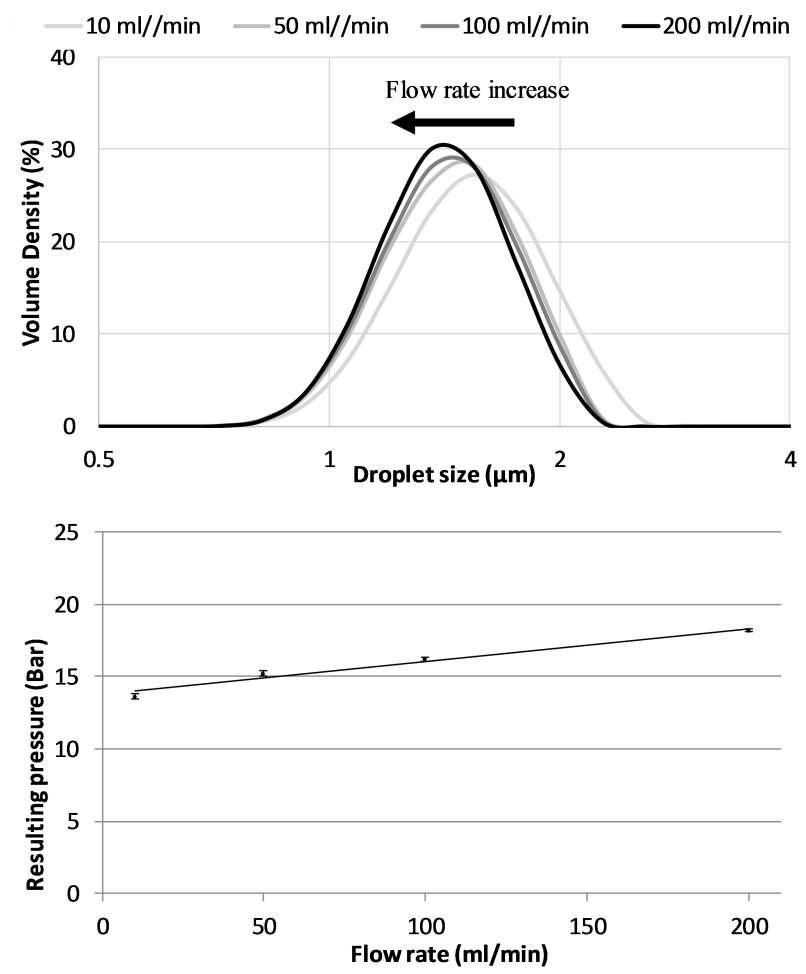

Figure 4: Effet of flow rate on the droplet size distribution (top) and the resulting pressure (bottom) for the preparation of MCT oil droplets by premix emulsification with membranne of $1.1 \mu \mathrm{m}$ pore size, for flow rates of $10,50,100,200 \mathrm{ml} / \mathrm{min}$

with microfluidic device which is a major limitation of this method [26]. Furthermore, larger volumes can be manipulated with the PME (10-200 ml/min), while the microfluidic devices have the ability to flow only smaller volumes on the order of $\mu \mathrm{l} / \mathrm{min}$. Although our membrane emulsification device cannot reach the high narrow size distribution (CV: 5\%) of microfluidic devices, our PME technique presents a relative homogeneous distribution $(\mathrm{CV}<20 \%)$, and is therefore a very promising technique to scale up the production of ADV emulsion for pharmaceutical manufacturers.

\subsubsection{Effect of dispersed phase type}

The effect of the dispersed phase type was investigated for PFHex, PFHep, MCT oil and a mix of PFHex:MCT oil (50/50 vol\%). The variation of the resulting pressure and the droplet size versus the dispersed phase type is shown in Figure 5 and Figure 6 , respectively.

The resulting pressure was similar for both PFCs, with 38.4 bars for PFHex and 37.8 bars for PFHep, but lower for the MCT oil with 19.5 bars. As detailed previously, the resulting pressure is mainly the sum of $\Delta P_{\text {flow }}$ and $\Delta P_{\text {disruption, }}$, given by the following equations [31, 39]:

$$
\Delta P_{\text {flow }}=\eta_{e} R_{m} J
$$

where $\eta_{e}$ is the emulsion viscosity in the pores, $R_{m}$ is the membrane resistance, $\mathrm{J}$ is the transmembrane 
flux, and

$$
\Delta P_{\text {disruption }}=C \varphi \gamma_{e q}\left(\frac{1}{D_{d}}-\frac{1}{D_{\text {premix }}}\right)
$$

where $\mathrm{C}$ is a constant, $\varphi$ is the volume fraction of the dispersed phase in the emulsion, $\gamma_{e q}$ is the interfacial tension at the equilibrium between dispersed phase and continuous phase, $D_{d}$ is the final droplet diameter and $D_{\text {premix }}$ is the premix droplet diameter [39. The viscosity is in the range of 25-32 mPa.s for MCT oil, droplets until the ADV threshold, where microbubbles were formed and the signal intensity increased. In contrast, bubbles are stronger scatterers, with responses several orders of magnitude higher compared with 


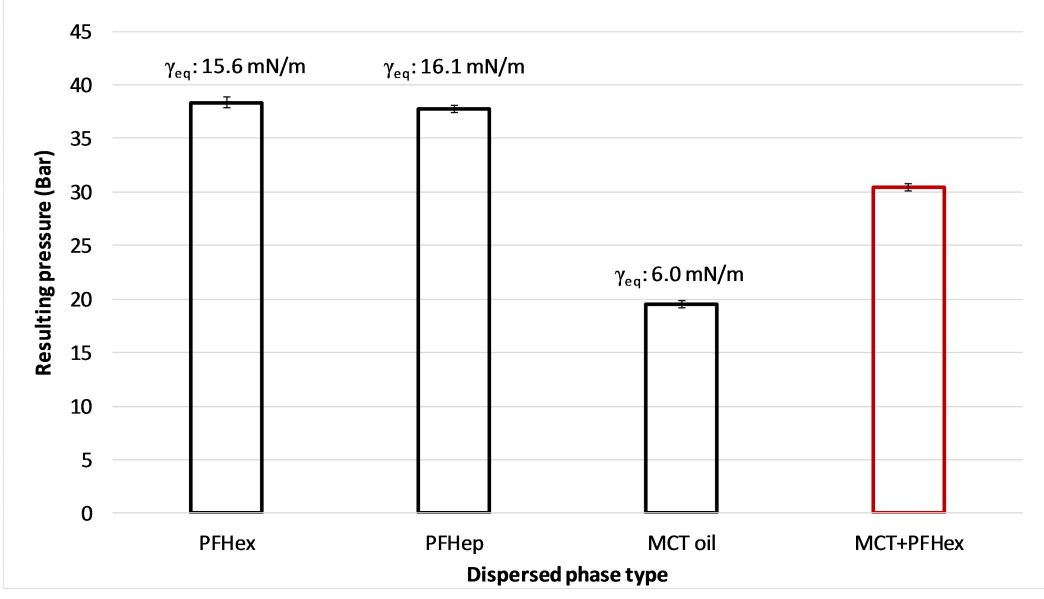

Figure 5: Resulting pressure as function of the dispersed phase type for the preparation of droplets by premix emulsification with pore size of $1.1 \mu \mathrm{m}$, for PFHex: PFHexane $\left(C_{6} F_{14}\right)$, PFHep: PFHeptane $\left(C_{7} F_{16}\right)$, MCT oil, and a mix of PFHex:MCT oil $(50 / 50 \mathrm{vol} \%)$. The histogram bars are the interfacial tension at the equilibrium, $\gamma_{e q}$, between the dispersed phase and the continuous phase of $2.0 \mathrm{wt} \%$ Tween:PEG40S

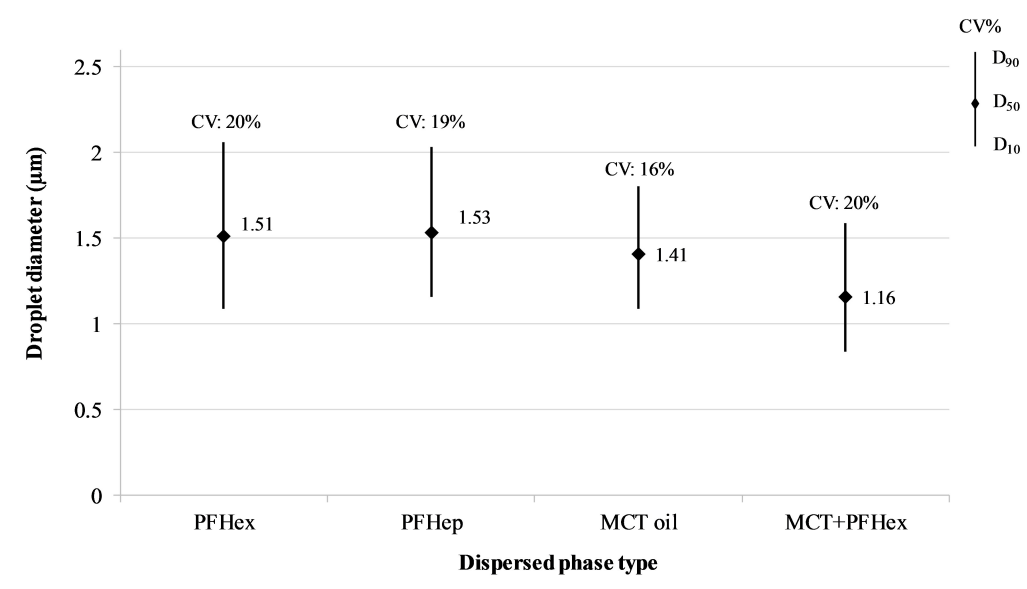

Figure 6: Droplet size as function of various dispersed phase types PFHex, PFHep, MCT oil and mixture of PFHex:MCT oil (50/50 vol\%) prepared by premix emulsification with pore size of $1.1 \mu \mathrm{m}$ at $200 \mathrm{~mL} / \mathrm{min}$. Above the histogram bars are the coefficent of variation of the droplet size distribution

droplets. The phase change from liquid to gas can be easily detected by the pulse-echo method. The phase change of droplets into microbubbles leads to increased echogenicity due to the ultrasound waves. Droplets can be vaporized in a medium at a temperature below their boiling point $\left(56^{\circ} \mathrm{C}\right)$. Microbubbles then formed a microbubbles cloud that rose-up at the water surface when the ultrasound pulses are stopped.

Aliabouzar et al. 42] summarized some ADV thresholds of droplets reported in the literature using acoustical and optical techniques. These ADV thresholds were obtained with different vaporization experimental set-ups, different droplets formulations, size and size distributions, and manufacturing protocols, which were assessed with different thresholding methods making comparisons with our data difficult. There are how- 
ever similarities between our study and the Kripfgans's studies 1, 9, where they investigated the droplet vaporization with an experimental set-up similar to ours, using a similar excitation frequency and the MEA of the images in B-mode of the suspension of droplets to assess the vaporization threshold. In the cited Kripfgans's studies, ADV thresholds between $0.7 \mathrm{MPa}$ and $1.5 \mathrm{MPa}$ at $7.5 \mathrm{MHz}$ were reported, very close to the thresholds found in our study (1.4 MPa, Table 1 of the manuscript). The main difference between our and the Kripfgans's studies is the PFC used to manufacture the droplets. Our droplets were composed of PFHex, which is a PFC with higher boiling point than the PFP used in the Kripfgans's studies. It was therefore expected that the ADV thresholds would be higher than the ADV thresholds obtained with PFP, a trend that was observed by Fabiilli et al. in their study of the influence of the PFC type on ADV threshold [21]. Similar trends have recently been also reported with PFHex microdroplets [4], with vaporization thresholds of 1.5-1.6 MPa at $10 \mathrm{MHz}$.

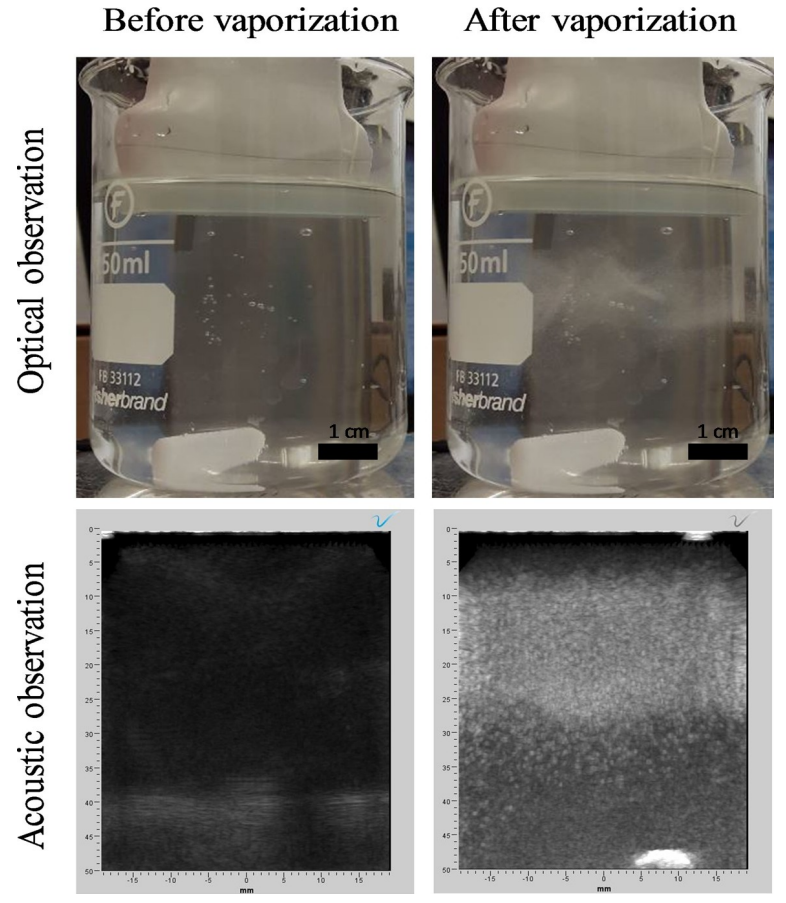

Figure 7: Optical and acoustic images of beaker filled with a PFHex droplet solution at $37^{\circ} \mathrm{C}$ before and after the ADV threshold vaporization. The droplet vaporization and formation of microbubbles opacified the solution and increased the echogenicity

\subsubsection{Effect of process on the droplet vaporization threshold}

The size and size distribution of ADV droplets are important factors that define the ADV threshold, and will also influence the biodistribution in the bloodstream during future pre-clinical studies. Generally, the ADV threshold is determined with polydispersed droplets obtained by conventional processes [1, 21]. As smaller droplets require more ultrasound energy to be vaporized, the large size distribution can influence the threshold energy for smaller droplets. The microbubble formation from large droplets may have an impact on the vaporization of smaller droplets due to the attenuation of the incident ultrasound waves by the 
Table 1: Influence of the various parameters on the ADV threshold

\begin{tabular}{|c|c|c|c|c|}
\hline Continuous phase & Dispersed phase & Parameters studied & Droplet size (CV\%) & ADV threshold \\
\hline \multirow{6}{*}{$\begin{array}{l}2 \mathrm{wt} \% \\
\text { Tween20:PEG40S }\end{array}$} & PFHexane & Droplet size & $1.19 \mu \mathrm{m}(21 \%)$ & $1.58 \mathrm{MPa}$ \\
\hline & & & $1.51 \mu \mathrm{m}(20 \%)$ & $1.49 \mathrm{MPa}$ \\
\hline & & & $4.41 \mu \mathrm{m}(19 \%)$ & $1.34 \mathrm{MPa}$ \\
\hline & & Temperature $\left(37^{\circ} \mathrm{C}\right.$ or $\left.25^{\circ} \mathrm{C}\right)$ & $1.51 \mu \mathrm{m}(20 \%)$ & Not reached at $25^{\circ} \mathrm{C}$ \\
\hline & PFHeptane & Perfluorocarbon (PFHep) & $1.53 \mu \mathrm{m}(19 \%)$ & $1.89 \mathrm{MPa}$ \\
\hline & PFHex:MCT oil & Mix with oil & $1.16 \mu \mathrm{m}(20 \%)$ & $2.24 \mathrm{MPa}$ \\
\hline
\end{tabular}

bubble cloud, or could trigger the vaporization of smaller droplets, resulting in an apparent lower threshold that would be expected. In that sense, the narrow size distribution will provide a tight control over the vaporization process, to avoid underisable effets, such as occlusion of unwanted vessels if ADV is used for embolotherapy.

Figure 8 a) shows the acoustic response of polydispersed and uniform-sized droplets. The polydispersed emulsion was produced by ultra-turrax (premix emulsion) and had a mean droplet size of $16.0 \mu \mathrm{m}$ and coefficient of variation of $41 \%$. The homogeneous emulsion was obtained by membrane emulsification $\left(D_{\text {pore }}\right.$ : $1.1 \mu \mathrm{m}$ ) with a mean droplet size of $1.51 \mu \mathrm{m}$ and coefficient of variation of $20 \%$. The homogeneous emulsion, having a smaller mean diameter and narrower distribution than the polydispersed one, led to a uniform response in the focal region of the transducer, while polydispersed droplets showed a more diffuse response with the vaporization of droplets outside the focal region.

Figure 8 b) shows droplet vaporization in this interest zone with the increasing acoustic pressure for uniform-sized and polydispersed droplets. In this comparison, when size distribution increases, the vaporization occurs a larger range of pressure compared to homogeneous emulsions. For the uniform-sized sample, no microbubbles were detected at low acoustic pressure, indicating the absence of droplet phase change under exposure to ultrasound. In the polydispersed sample however, echogenic microbubbles were observed at lower acoustic pressure, probably due to the vaporization of larger droplets.

Indeed on the Figure $8 \mathrm{c}$ ), the REA value increased sharply (leading coefficient: 2.78) while the applied pressure was below the ADV threshold for polydispersed droplets, while for the uniform-sized sample, a slight increase of REA was observed with a leading coefficient around 0.32 . For all experiments with uniform-sized droplets, the REA was found to increase slightly before the ADV threshold, with a leading coefficient around 0.8. Kripfgans et al. [1] observed similar phenomenon with dodecafluoropentane droplets stabilized with 
a)

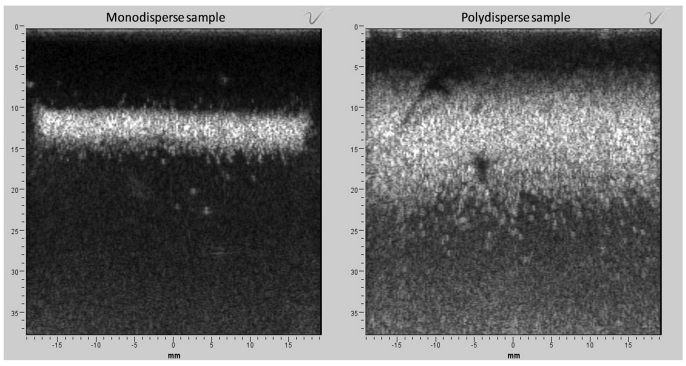

b)

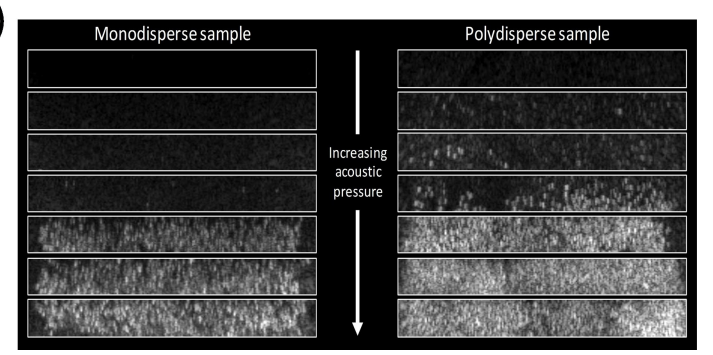

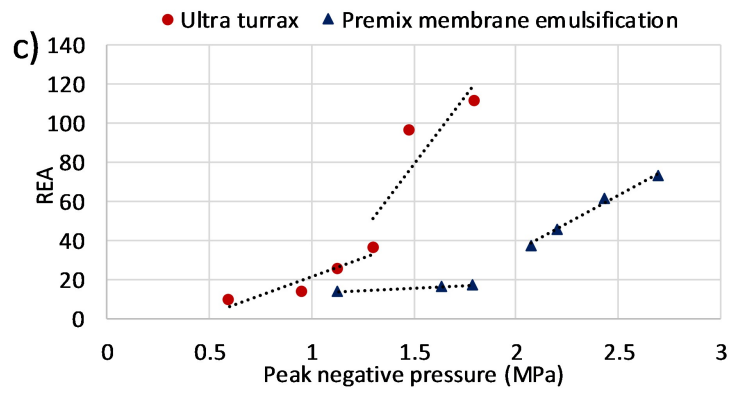

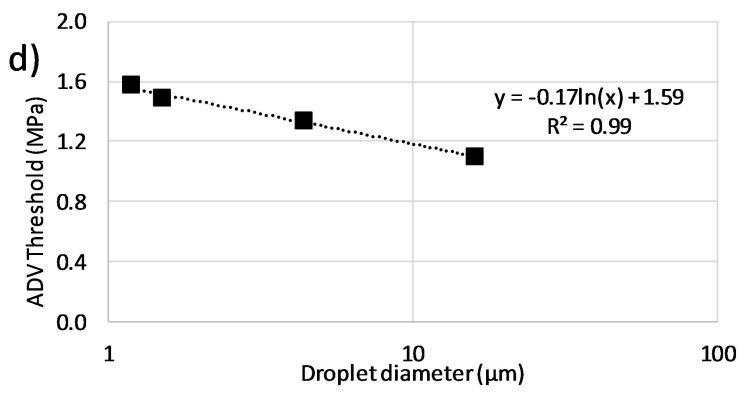

Figure 8: a) Acoustic observation of the vaporization of uniform-sized and polydispersed sample containing PFHex droplets in the region of interest of the transducer at ultrasound pressure corresponding at $2.82 \mathrm{MPa}$, and b) the region of interest at increasing ultrasound pressure. c) Relative echo amplitude (REA) for uniform-sized and polydispersed sample containing PFHex droplets as function of ultrasound probe driving acoustic pressure. d) Influence of PFHex droplet size on the ADV threshold at $37^{\circ} \mathrm{C}$ prepared by premix emulsification at $200 \mathrm{~mL} / \mathrm{min}$

bovine serum albumin and produced by a high-speed vial shaker. Thus, this variability in the increase in REA due to the large size distribution, leads the evaluation of activation thresholds challenging and results in great variability in the determination of ADV threshold. In our case, the slight increase of REA could be radii of $1.19,1.51$, and $4.41 \mu \mathrm{m}$ were vaporized at an $\mathrm{ADV}$ threshold of $1.58,1.49$ and $1.34 \mathrm{MPa}$, respectively. On Figure 8d), it appears that a negative logarithmic relation between droplet size and vaporization energy $\left(\mathrm{Y}=-0.17 \ln (\mathrm{X})+1.59, R^{2}=0.99\right)$ as predicted by the Antoine's equation linking the pressure and the 
temperature of vaporization [10, 44, 45]:

$$
\log P=A-\frac{B}{T+C}
$$

where $\mathrm{P}$ is pressure, $\mathrm{T}$ is temperature and $\mathrm{A}, \mathrm{B}$, and $\mathrm{C}$ are gas-dependent constants. Furthermore, the Laplace pressure is an inverse function of droplet size, thus smaller droplets have a higher boiling temperature than larger droplets. Thus, uniform-sized droplets produced by PME responded similarly to the same acoustic parameters in the focal region of the transducer. As suggested by Martz et al. [10] and recently reported by Moncion et al. [46], other advantages of uniform-sized droplets could be the ability to adapt ADV droplet sizes for applications such as specific vessel occlusion or on-demand drug release.

\subsubsection{Effect of the temperature}

We investigated the effect of temperature on the vaporization threshold of our droplets formulation, and found behavior consistent with the literature [21, 47]. The boiling point of perfluorocarbon can be increased inside droplets due to the Laplace pressure [4]. For PFP droplets, containing perfluoropentane whose natural boiling point is $29^{\circ} \mathrm{C}$, there is a critical diameter below which the boiling temperature of the PFP is increased above $37 \mathrm{C}$. Larger PFP droplets will be in a superheated state, and it was recently proposed that the stability of superheated PFC droplets could be due to the energy barrier for homogeneous nucleation, rather than the Laplace pressure [48. In the case of PFHex, because their boiling point $\left(56^{\circ} \mathrm{C}\right)$ is higher than the two temperatures investigated $\left(25^{\circ} \mathrm{C}\right.$ and $\left.37^{\circ} \mathrm{C}\right)$, droplets are not in a superheated state.

Figures 9 shows that droplets vaporization was affected by temperature. Vaporization was observed at $37^{\circ} \mathrm{C}$, while at $25^{\circ} \mathrm{C}$, the ADV threshold was not reached as shown by the absence of a sharp increase of REA. Similar results were reported by Fabiili et al. 21], where no ADV was observed for PFHex droplets at $25^{\circ} \mathrm{C}$ below the boiling point. Also, these authors showed a decrease of the ADV threshold when increasing the sample temperature. Once the superheated state was reached, the sample temperature had no effect on the

ADV threshold. Our study shows the possible vaporization of ADV droplets with a high boiling temperature of PFC at body temperature but not at room temperature.

\subsubsection{Effect of perfluorocarbon type}

The ADV thresholds for the different PFCs (PFHex or PFHep) at $37^{\circ} \mathrm{C}$ are presented in Table 1. For similar droplets size $(1.51 \mu \mathrm{m}$ for PFHex and $1.53 \mu \mathrm{m}$ for PFHep), the ADV threshold was lower for PFHex droplets with an ADV threshold of 1.49 MPa, than PFHep droplet with an ADV threshold of 1.89 MPa. Despite the high boiling point of PFHep $\left(80^{\circ} \mathrm{C}\right)$, we observed the vaporization of PFHep droplets. PFC droplets being in a non superheated state, their ADV threshold was proportional to their boiling temperature. Indeed, the PFC with a higher boiling point requires more activation energy to vaporize the droplets as predicted by Antoine's equation (Equation 9). In therapeutic applications of ultrasound, high pressures are used to create desired bioeffects, thus PFC with a high boiling temperature may be more suitable, as droplets should remain stable until their activation. 

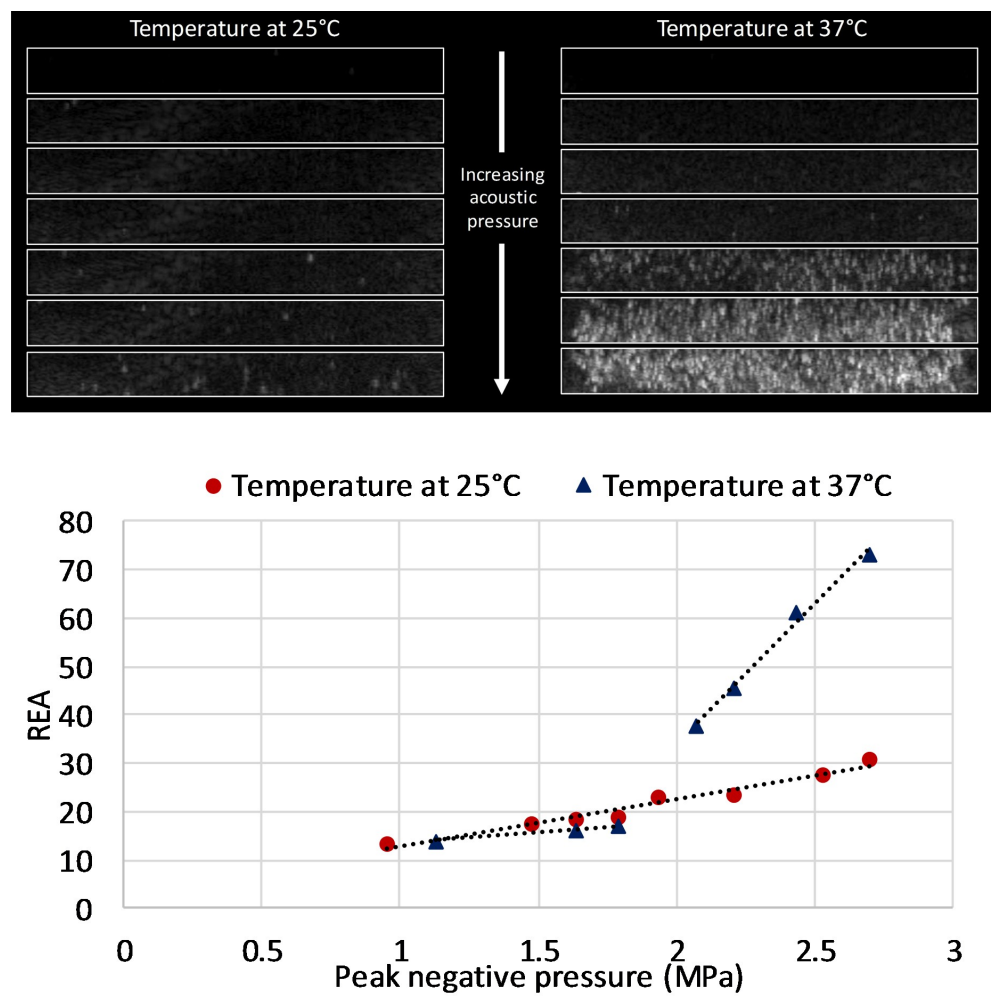

Figure 9: Influence of temperature on the ADV process: Vaporization response in the region of the interest of PFHex droplets (top) and Relative echo amplitude (REA) (bottom) as function of ultrasound propbe driving acoustic pressure, at $25^{\circ} \mathrm{C}$ and $37^{\circ} \mathrm{C}$

\subsubsection{Effect of the presence of oil}

Dual-phase droplets were prepared by the premix emulsification using a PFHex:MCT oil mixture (50/50 vol\%) stabilized by 2.0wt\% Tween20:PEG40S solution (molar ratio 9:1). Figure 10 shows these dual-phase droplets observed by optical microscopy with two distinct phases. Indeed, a MCT oil layer envelops the PFHex phase due to their difference of hydrophobicity. As reported by Riess 2001 49, PFCs are significantly more hydrophobic than hydrocarbons compounds and are not only hydrophobic but lipophobic as well. This emulsion was obtained with the premix technique, as the small droplets obtained by PME were not observable by optical microscopy.

Table 1 summarizes the ADV thresholds obtained for droplets with similar size: around $1.16 \mu \mathrm{m}$ for dual-phase droplets and $1.19 \mu \mathrm{m}$ for PFHex droplets. The ADV threshold for the dual-phase droplets was 2.24 MPa, while PFHex droplets had a lowerer ADV threshold of 1.58 MPa. This oil layer of PFHex core has an influence on the ADV threshold and require more activation energy for vaporization. This may result from the presence of medium chain triglycerides within the dual-phase droplets that helps to stabilize the PFHex phase. An explanation of the increase of ADV threshold for dual-phase droplets, could be the inhibition of the expansion of any gas nuclei generated within the PFHex phase during the ultrasound waves exposure, leading to a possible recondensation of PFHex. Fabiilli et al. 21] observed similar results, with an increase 
of the ADV threshold by increasing the viscosity of the bulk fluid by adding glycerol in the water phase. Furthermore, as observed with the size effect on the threshold, the PFC core size is smaller in the dualphase for similar droplet size with PFC core alone, necessarily leading an increase of ADV threshold. Thus, the oil layer thickness may vary within each droplet which could influence the ADV threshold. For future experiments where the droplets will be loaded with drugs, it would be interesting to observe the effect of vaporization on the drug activity, as a possible damage of the drug within the oil phase could occur during the vaporization of the PFHex core.
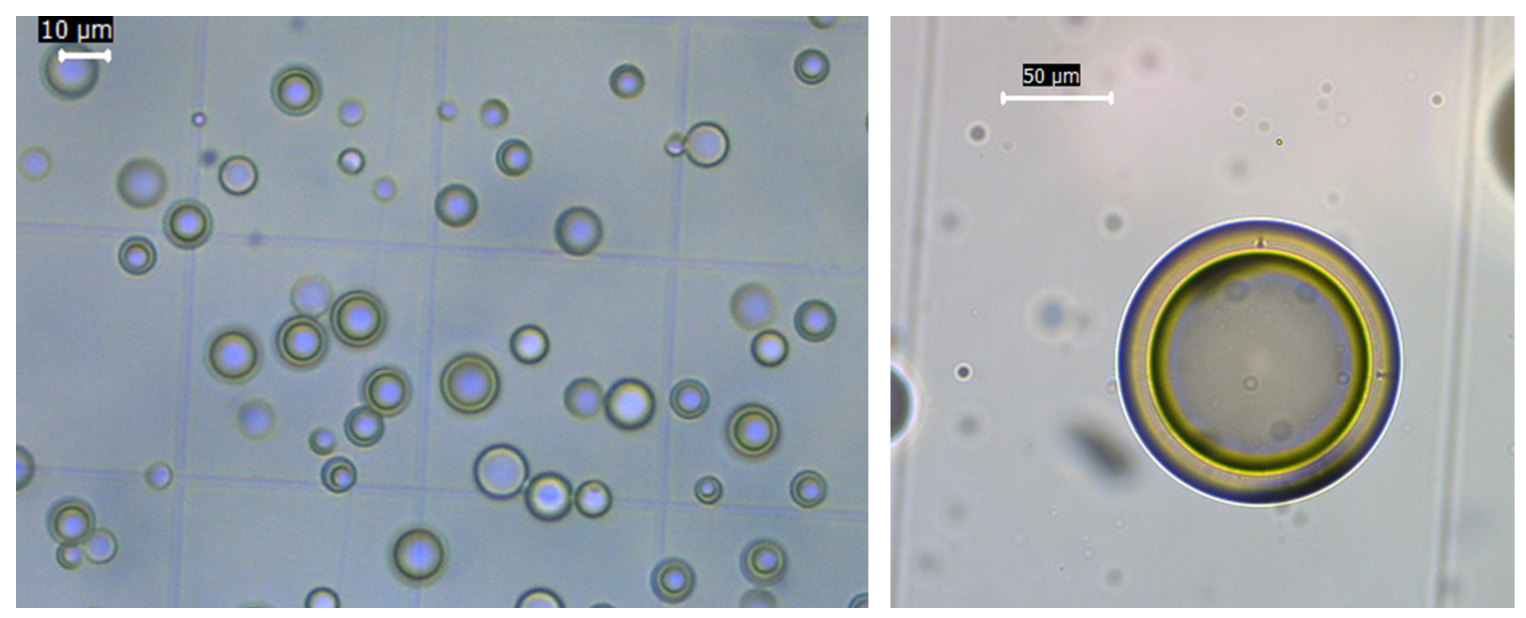

Figure 10: Optical microscopy observation of the dual-phase (PFHex:MCT oil) droplets from premix emulsion sample

\section{Conclusion}

This work described the production of uniform-sized PFC droplets for acoustic droplet vaporization by PME. It presents a new approach to optimize and manufacture narrow size droplets with potential GMP production and clinical transition. PFC droplets were formed by break-up of larger droplets in a SPG membrane at high flow rate $(200 \mathrm{~mL} / \mathrm{min})$. The high yield of droplets obtained, $10^{+12}$ Droplets/s, is one key advantage of the proposed process for large scale preparation of PFC emulsions. With a membrane pore size of 3.1, 1.1 and $0.8 \mu \mathrm{m}$, the size, CV and span of the manufactured droplets were 4.41, 1.51 and $1.19 \mu \mathrm{m}, 20 \%$ and 0.6 , respectively. These emulsions obtained had droplet size distribution below $10 \mu \mathrm{m}$ and so would be suitable for bloodstream injection for pre-clinical ADV studies. We investigated the effect of several process parameters on the resulting pressure and droplet size: membrane pore size, flow rate, and dispersed phase type. A slight decrease of droplet size with flow rate was obtained due to a higher wall shear stress at the membrane pore walls, which facilitates droplet disruption. Moreover, a linear relationship between droplet size and pore size was found, while a sharp increase of the resulting pressure was observed when decreasing the membrane pore size. With the addition of MCT oil in the dispersed phase, the pressure required for the premix to flow through the membrane was reduced and minimized, allowing the use of membranes with 
430 A first proof of concept of feasibility was demonstrated with a mixture of PFHex:MCT oil (50/50 vol\%) to prepare dual-phase droplets, where a MCT oil surrounds the PFC core as observed by optical microscopy.

Uniform-sized PFC droplets exposed to ultrasound showed a uniform ADV response, while polydispersed droplets presented a more diffuse response outside the focal region of the transducer. The relationship between droplet size and the ADV threshold seems to be in agreement with an expected negative logarithmic variation. PFC droplets being in a non superheated state, the bulk fluid temperature had an influence on the ADV threshold, and vaporization was observed only at a physiological temperature, but not at room temperature. The ADV threshold was proportional to the boiling temperature of PFC, with higher ADV threshold for PFHep than for PFHex. The dual-phase droplets is an interesting alternative to monophase 440

the of membranes with smaller pores size to obtain smaller droplets. 


\section{Nomenclature}

$\begin{array}{ll}\text { A } & \text { Signal at pixel (i,j) } \\ A, B, C & \text { Gas dependent constants } \\ D_{i} & \text { Mean diameter in the class i }(\mu \mathrm{m}) \\ D_{n} & \text { Droplet diameter at } \mathrm{n} \% \text { of the cumulative number }(\mu \mathrm{m}) \\ D_{d} & \text { Final droplet diameter }(\mu \mathrm{m}) \\ D_{\text {premix }} & \text { Premix droplet diameter }(\mu \mathrm{m}) \\ D_{p} & \text { Pore diameter }(\mu \mathrm{m}) \\ \mathrm{J} & \text { Transmembrane flux }\left(m^{3} \cdot m^{-2} \cdot s^{-1}\right) \\ n & \text { Frame number } \\ n_{i} & \text { Number of droplets in the class i } \\ R_{m} & \text { Membrane resistance }\left(m^{-1}\right) \\ \Delta P_{\text {disruption }} & \text { Disruption pressure (bar) } \\ \Delta P_{f l o w} & \text { Flow pressure (bar) } \\ \Delta P_{\text {pipe }} & \text { Pipe pressure (bar) } \\ \Delta P_{r} & \text { Resulting pressure (bar) } \\ \delta & \text { Standard deviation } \\ \varepsilon & \text { Membrane porosity } \\ \xi & \text { Pore tortuosity } \\ \varphi & \text { Volume fraction of dispersed phase } \\ \gamma_{\text {eq }} & \text { Interfacial tension at the equilibrium }\left(m N . m^{-1}\right) \\ \eta_{e} & \text { Viscosity of the emulsion }(\text { Pa.s }) \\ \tau_{w, p} & \text { Wall shear stress }(\text { Pa) }\end{array}$




\section{Abreviations}

ADV Acoustic droplet vaporization

CV Coefficient variation

DME Direct membrane emulsification

MCT Medium chain triglyceride

MEA Mean echo amplitude

PEG40S Polyoxyethylene (20) stearate

PFC Perfluorocarbone

PFHex Perfluorohexane, $C_{6} F_{14}$

PFHep Perfluoroheptane, $C_{7} F_{16}$

PFP Perfluoropentane, $C_{5} F_{12}$

PME Premix membrane emulsification

PRF Pulse repetition frequencies

REA Relative echo amplitude

ROI Region of interest

SPG Shirasu Porous Glass

Tween20 Polyoxyethylene (20) sorbitan monolaurate

US Ultrasound

\section{References}

[1] O. D. Kripfgans, J. B. Fowlkes, D. L. Miller, O. P. Eldevik, P. L. Carson, Acoustic droplet vaporization for therapeutic and diagnostic applications, Ultrasound in Medicine \& Biology 26 (7) (2000) 1177-1189.

[2] Mark T. Burgess, Tyrone M. Porter, On-Demand cavitation fromm bursting droplets, Acoustics Today $11(2015) 35-41$.

[ [3] O. Kripfgans, C. Orifici, P. Carson, K. Ives, O. Eldevik, J. Fowlkes, Acoustic droplet vaporization for temporal and spatial control of tissue occlusion: a kidney study, IEEE Transactions on Ultrasonics, Ferroelectrics and Frequency Control 52 (7) (2005) 1101-1110. doi:10.1109/TUFFC.2005.1503996. URL http://ieeexplore.ieee.org/document/1503996/

[4] G. M. Lanza, S. A. Wickline, Targeted ultrasonic contrast agents for molecular imaging and therapy, Progress in Cardiovascular Diseases 44 (1) (2001) 13-31. doi:10.1053/pcad.2001.26440.

URL http://linkinghub.elsevier.com/retrieve/pii/S0033062001000160

[5] D. R. Evans, D. F. Parsons, V. S. J. Craig, Physical Properties of Phase-Change Emulsions, Langmuir 22 (23) (2006) 9538-9545. doi:10.1021/la062097u

URL http://pubs .acs .org/doi/abs/10.1021/la062097u 
[6] M. Zhang, M. L. Fabiilli, K. J. Haworth, F. Padilla, S. D. Swanson, O. D. Kripfgans, P. L. Carson, J. B. Fowlkes, Acoustic Droplet Vaporization for Enhancement of Thermal Ablation by High Intensity Focused Ultrasound, Academic Radiology 18 (9) (2011) 1123-1132. doi:10.1016/j . acra.2011.04.012. URL http://linkinghub.elsevier .com/retrieve/pii/S1076633211002170

[7] T. Segers, Monodisperse bubbles and droplets for medical applications, University of Twente, Enschede, 2015, oCLC: 910511293.

[8] P. S. Sheeran, P. A. Dayton, Phase-change contrast agents for imaging and therapy, Current Pharmaceutical Design 18 (15) (2012) 2152-2165.

[9] O. D. Kripfgans, J. B. Fowlkes, M. Woydt, O. P. Eldevik, P. L. Carson, In vivo droplet vaporization for occlusion therapy and phase aberration correction, IEEE transactions on Ultrasonics, Ferroelectrics, and Frequency Control 49 (6) (2002) 726-738.

[10] T. D. Martz, P. S. Sheeran, D. Bardin, A. P. Lee, P. A. Dayton, Precision Manufacture of Phase-Change Perfluorocarbon Droplets Using Microfluidics, Ultrasound in Medicine \& Biology 37 (11) (2011) 19521957. doi:10.1016/j.ultrasmedbio.2011.08.012

URL http://linkinghub.elsevier.com/retrieve/pii/S0301562911013081

[11] M. L. Fabiilli, K. J. Haworth, I. E. Sebastian, O. D. Kripfgans, P. L. Carson, J. B. Fowlkes, Delivery of Chlorambucil Using an Acoustically-Triggered Perfluoropentane Emulsion, Ultrasound in Medicine \& Biology 36 (8) (2010) 1364-1375. doi:10.1016/j.ultrasmedbio.2010.04.019. URL http://linkinghub.elsevier.com/retrieve/pii/S0301562910002188

[12] M. L. Fabiilli, C. G. Wilson, F. Padilla, F. M. Martn-Saavedra, J. B. Fowlkes, R. T. Franceschi, Acoustic droplethydrogel composites for spatial and temporal control of growth factor delivery and scaffold stiffness, Acta Biomaterialia 9 (7) (2013) 7399-7409. doi:10.1016/j.actbio.2013.03.027 URL http://linkinghub.elsevier.com/retrieve/pii/S1742706113001451

[13] Rajian Justin R., Fabiilli Mario L., Fowlkes J. Brian, Carson Paul L., Wang Xueding, Drug delivery monitoring by photoacoustic tomography with an ICG encapsulated double emulsion, Optics Express 19 (2011) 14335-14347. doi:10.1364/0E.19.014335.

[14] C.-H. Wang, S.-T. Kang, Y.-H. Lee, Y.-L. Luo, Y.-F. Huang, C.-K. Yeh, Aptamer-conjugated and drug-loaded acoustic droplets for ultrasound theranosis, Biomaterials 33 (6) (2012) 1939-1947. doi: $10.1016 / j$. biomaterials.2011.11.036 URL http://linkinghub.elsevier.com/retrieve/pii/S0142961211013901

[15] O. D. Kripfgans, M. Zhang, M. L. Fabiilli, P. L. Carson, F. Padilla, S. D. Swanson, C. Mougenot, J. Brian Fowlkes, C. Mougenot, Acceleration of ultrasound thermal therapy by patterned acoustic droplet vaporization, The Journal of the Acoustical Society of America 135 (1) (2014) 537-544. 
[16] O. Kripfgans, C. Orifici, P. Carson, K. Ives, O. Eldevik, J. Fowlkes, Acoustic droplet vaporization for temporal and spatial control of tissue occlusion: a kidney study, IEEE Transactions on Ultrasonics, Ferroelectrics and Frequency Control 52 (7) (2005) 1101-1110. doi:10.1109/TUFFC.2005.1503996. URL http://ieeexplore.ieee.org/document/1503996/

[17] O. Shpak, L. Stricker, T. Kokhuis, Y. Luan, B. Fowlkes, M. Fabiilli, D. Lohse, N. de Jong, M. Versluis, Ultrafast dynamics of the acoustic vaporization of phase-change microdroplets, The Journal of the Acoustical Society of America 133 (5) (2013) 3586-3586. doi:10.1121/1.4806609.

URL http://asa.scitation.org/doi/10.1121/1.4806609

[18] J. M. M. Simons, L. M. Kornmann, K. D. Reesink, A. P. G. Hoeks, M. F. Kemmere, J. Meuldijk, J. T. F. Keurentjes, Monodisperse perfluorohexane emulsions for targeted ultrasound contrast imaging, Journal of Materials Chemistry 20 (19) (2010) 3918. doi:10.1039/b922437h

URL http://xlink.rsc.org/?DOI=b922437h

[19] R. Williams, C. Wright, E. Cherin, N. Reznik, M. Lee, I. Gorelikov, F. S. Foster, N. Matsuura, P. N. Burns, Characterization of Submicron Phase-change Perfluorocarbon Droplets for Extravascular Ultrasound Imaging of Cancer, Ultrasound in Medicine \& Biology 39 (3) (2013) 475-489. doi: 10.1016/j.ultrasmedbio.2012.10.004.

URL http://linkinghub.elsevier.com/retrieve/pii/S030156291200614X

[20] S.-T. Kang, Y.-L. Huang, C.-K. Yeh, Characterization of Acoustic Droplet Vaporization for Control of Bubble Generation Under Flow Conditions, Ultrasound in Medicine \& Biology 40 (3) (2014) 551-561. doi:10.1016/j.ultrasmedbio.2013.10.020. URL http://linkinghub.elsevier.com/retrieve/pii/S0301562913011137

[21] M. L. Fabiilli, K. J. Haworth, N. H. Fakhri, O. D. Kripfgans, P. L. Carson, J. B. Fowlkes, The role of inertial cavitation in acoustic droplet vaporization, IEEE transactions on Ultrasonics, Ferroelectrics, and Frequency Control 56 (5) (2009) 1006-1017.

${ }_{520}[22]$ M. L. Fabiilli, J. A. Lee, O. D. Kripfgans, P. L. Carson, J. B. Fowlkes, Delivery of Water-Soluble Drugs Using Acoustically Triggered Perfluorocarbon Double Emulsions, Pharmaceutical Research 27 (12) (2010) 2753-2765. doi:10.1007/s11095-010-0277-5.

URL http://link.springer.com/10.1007/s11095-010-0277-5

[23] T. Giesecke, K. Hynynen, Ultrasound-mediated cavitation thresholds of liquid perfluorocarbon droplets 525 in vitro, Ultrasound in Medicine \& Biology 29 (9) (2003) 1359-1365. doi:10.1016/S0301-5629(03) 00980-3.

URL http://linkinghub.elsevier.com/retrieve/pii/S0301562903009803 
[24] K. P. Mercado, K. Radhakrishnan, K. Stewart, L. Snider, D. Ryan, K. J. Haworth, Size-isolation of ultrasound-mediated phase change perfluorocarbon droplets using differential centrifugation, Journal of the Acoustical Society of America 139 (5) (2016) 142-148. doi:10.1121/1.4946831.

URL http://asa.scitation.org/doi/10.1121/1.4946831

[25] A. Lo, O. Kripfgans, P. Carson, E. Rothman, J. Fowlkes, Acoustic droplet vaporization threshold: effects of pulse duration and contrast agent, IEEE Transactions on Ultrasonics, Ferroelectrics and Frequency Control 54 (5) (2007) 933-946. doi:10.1109/TUFFC.2007.339.

URL http://ieeexplore.ieee.org/document/4225305/

[26] P. S. Sheeran, N. Matsuura, M. A. Borden, R. Williams, T. O. Matsunaga, P. N. Burns, P. A. Dayton, Methods of generating submicrometer phase-shift perfluorocarbon droplets for applications in medical ultrasonography, IEEE transactions on ultrasonics, ferroelectrics, and frequency control 64 (1) (2017) 252-263. doi:10.1109/TUFFC.2016.2619685.

[27] G. T. Vladisavljević, Integrated membrane processes for the preparation of emulsions, particles and bubbles, Integrated Membrane Systems and Processes 79 (2015) 79-140.

[28] C. Charcosset, Membranes for the preparation of emulsions and particles, in: Membrane Processes in Biotechnology and Pharmaceutics, Elsevier, 2012, pp. 213-251. doi:10.1016/B978-0-444-56334-7. 00006-X. URL http://linkinghub.elsevier.com/retrieve/pii/B978044456334700006X

[29] M. Kukizaki, Y. Baba, Effect of surfactant type on microbubble formation behavior using Shirasu porous glass (SPG) membranes, Colloids and Surfaces A: Physicochemical and Engineering Aspects 326 (3) (2008) 129-137. doi:10.1016/j.colsurfa.2008.05.025. URL http://www.sciencedirect.com/science/article/pii/S0927775708003452

[30] R. Melich, J.-P. Valour, S. Urbaniak, F. Padilla, C. Charcosset, Preparation and characterization of perfluorocarbon microbubbles using Shirasu Porous Glass (SPG) membranes, Colloids and Surfaces A: ․ Physicochemical and Engineering Aspects. 560 (2019) 233-243. doi:10.1016/j.colsurfa.2018.09. 058 .

URL https://linkinghub.elsevier.com/retrieve/pii/S0927775718311658

[31] A. Nazir, K. Schroën, R. Boom, Premix emulsification: A review, Journal of Membrane Science 362 (1-2) (2010) 1-11. doi:10.1016/j.memsci.2010.06.044

URL http://linkinghub.elsevier .com/retrieve/pii/S0376738810005119

[32] O. Alliod, J.-P. Valour, S. Urbaniak, H. Fessi, D. Dupin, C. Charcosset, Preparation of oil-in-water 口. nanoemulsions at large-scale using premix membrane emulsification and Shirasu Porous Glass (SPG) 560 membranes, Colloids and Surfaces A: Physicochemical and Engineering Aspects. 557 (2018) 76-84. doi: 
$10.1016 / \mathrm{j} \cdot \mathrm{colsurfa} .2018 .04 .045$.

URL http://linkinghub.elsevier.com/retrieve/pii/S0927775718303212

[33] M. Kukizaki, M. Goto, Spontaneous formation behavior of uniform-sized microbubbles from Shirasu porous glass (SPG) membranes in the absence of water-phase flow, Colloids and Surfaces A: Physicochemical and Engineering Aspects 296 (1-3) (2007) 174-181. doi:10.1016/j.colsurfa.2006.09.042. URL http://linkinghub.elsevier.com/retrieve/pii/S092777570600731X

[34] T. Nakashima, M. Kawano, M. Shimizu, Articles of porous glass and process for preparing the same, US Patent No. 4,657,875, 1987.

[35] G. T. Vladisavljević, H. Schubert, Preparation and analysis of oil-in-water emulsions with a narrow droplet size distribution using Shirasu-porous-glass (SPG) membranes, Desalination 144 (2002) 167172. doi:10.1016/S0011-9164(02)00307-7

[36] J. H. Xu, S. W. Li, G. G. Chen, G. S. Luo, Formation of monodisperse microbubbles in a microfluidic device, AIChE Journal 52 (6) (2006) 2254-2259. doi:10.1002/aic.10824.

URL http://doi.wiley.com/10.1002/aic.10824

[41] G. Vladisavljević, M. Shimizu, T. Nakashima, Permeability of hydrophilic and hydrophobic Shirasuporous-glass (SPG) membranes to pure liquids and its microstructure, Journal of Membrane Science 
250 (1-2) (2005) 69-77. doi:10.1016/j.memsci.2004.10.017.

URL http://linkinghub.elsevier.com/retrieve/pii/S0376738804007112

[42] M. Aliabouzar, K. N. Kumar, K. Sarkar, Acoustic vaporization threshold of lipid-coated perfluoropentane droplets, The Journal of the Acoustical Society of America 143 (4) (2018) 2001-2012. doi:10.1121/1. 5027817.

URL http://asa.scitation.org/doi/10.1121/1.5027817

[43] M. Aliabouzar, K. N. Kumar, K. Sarkar, Effects of droplet size and perfluorocarbon boiling point on the frequency dependence of acoustic vaporization threshold, The Journal of the Acoustical Society of America 145 (2) (2019) 1105-1116.

[44] P. S. Sheeran, V. P. Wong, S. Luois, R. J. McFarland, W. D. Ross, S. Feingold, T. O. Matsunaga, P. A. Dayton, Decafluorobutane as a Phase-Change Contrast Agent for Low-Energy Extravascular Ultrasonic

1 I Imaging, Ultrasound in Medicine \& Biology 37 (9) (2011) 1518-1530. doi:10.1016/j.ultrasmedbio. 2011.05 .021

URL http://linkinghub.elsevier.com/retrieve/pii/S0301562911002833

[45] N. Y. Rapoport, A. L. Efros, D. A. Christensen, A. M. Kennedy, K.-H. Nam, Microbubble generation in phase-shift nanoemulsions used as anticancer drug carriers, Bubble Science, Engineering \& Technology 1 (1-2) (2009) 31-39. doi:10.1179/175889709X446516.

URL http://www .maneyonline.com/doi/abs/10.1179/175889709X446516

[46] A. Moncion, M. Lin, O. D. Kripfgans, R. T. Franceschi, A. J. Putnam, M. L. Fabiilli, Sequential payload release from acoustically-responsive scaffolds using focused ultrasound, Ultrasound in Medicine \& Biology 44 (11) (2018) 2323-2335. doi:10.1016/j.ultrasmedbio.2018.06.011. URL http://www.sciencedirect.com/science/article/pii/S0301562918302667

15 [47] A. S. Hannah, G. P. Luke, S. Y. Emelianov, Blinking phase-change nanocapsules enable background-free ultrasound imaging, Theranostics 6 (11) (2016) 1866-1876. doi:10.7150/thno.14961.

URL http://www .thno.org/v06p1866.htm

[48] P. A. Mountford, M. A. Borden, On the thermodynamics and kinetics of superheated fluorocarbon phase-change agents, Advances in colloid and interface science 237 (2016) 15-27.

[49] J. G. Riess, Oxygen carriers (blood substitutes), chemistry, and some physiology, Chemical Reviews 101 (9) (2001) 2797-2920. doi:10.1021/cr970143c URL http://pubs . acs .org/doi/abs/10.1021/cr970143c 